\title{
Effect of micromechanical stimulations on osteoblasts: development of a device simulating the mechanical situation at the bone-implant interface
}

\author{
Dominique P. Pioletti ${ }^{\mathrm{a}, *}$, Jan Müller ${ }^{\mathrm{b}}$, Lalao R. Rakotomanana ${ }^{\mathrm{c}}$, \\ Jacques Corbeil ${ }^{\mathrm{d}}$, Edmond Wild ${ }^{\mathrm{b}}$ \\ a Bone Bioengineering Group, Laboratory of Orthopaedic Research, Institute for Biomedical Engineering, Swiss Federal Institute of Technology, \\ Lausanne, Switzerland \\ ${ }^{\mathrm{b}}$ EIVD, School of Engineering, Yverdon, Switzerland \\ ' IRMAR, University of Rennes I, Rennes, France \\ ${ }^{\mathrm{d}}$ Department of Medicine, University of California San Diego, and San Diego Veterans Affairs Healthcare System, La Jolla, USA
}

Accepted 14 August 2002

\begin{abstract}
Many experimental models have been developed to investigate the effects of mechanical stimulation of cells, but none of the existing devices can simulate micromotions at the cellular-mechanical interface with varying amplitudes and loads. Osteoblasts are sensitive to mechanical stimuli, so to study the bone-implant interface it would be important to quantify their reaction in a situation mimicking the mechanical situation arising at that interface. In this study, we present the development of a new device allowing the application of micromotions and load on cells in vitro. The new device allowed the cells to be stimulated with sinusoidal motions of amplitudes comprised between \pm 5 and $\pm 50 \mu \mathrm{m}$, frequencies between 0.5 and $2 \mathrm{~Hz}$, and loads between 50 and $1000 \mathrm{~Pa}$. The device, with a total length of $20 \mathrm{~cm}$, was designed to work in an incubator at $37^{\circ} \mathrm{C}$ and $100 \%$ humidity. Expression of various bone important genes was monitored by real-time RT-PCR. Micromotions and load were shown to affect the behavior of osteoblasts by down-regulating the expression of genes necessary for the creation of organic extracellular matrix (collagen type I) as well as for genes involved in the mineralization process (osteocalcin, osteonectin). The developed device could then be used to simulate different mechanical situations at the bone-implant interface.
\end{abstract}

(C) 2002 Elsevier Science Ltd. All rights reserved.

Keywords: Mechanical stimuli; Osteoblast; Bone-implant interface; Cell mechanics; Gene expression

\section{Introduction}

The presence of a fibrous tissue around orthopedic implants is associated with implant loosening as this tissue is unable to resist shear stress which occurs at the bone-implant interface (Hori and Lewis, 1982). Two factors have been identified in the creation of this fibrous tissue, the presence of wear particles and the generation of micromotions at the bone-implant interface (Clarke et al., 1992; Goodman, 1994). The precise

*Corresponding author. Bone Bioengineering Group, IGBM, Bat. AAB, EPFL, 1015 Lausanne, Switzerland. Tel.: +41-21-693-83-41; fax: +41-21-693-86-60.

E-mail address: dominique.pioletti@epfl.ch (D.P. Pioletti). role of or correlation between these two factors in the tissue differentiation process remains to be determined (Aspenberg and Herbertsson, 1996).

Micromotions are important in the fate of tissue differentiation. Jasty et al., found that micromotions lower than $40 \mu \mathrm{m}$ favor bone formation, while micromotions higher than $100 \mu \mathrm{m}$ lead to the creation of a fibrous tissue (Jasty et al., 1997). Recent investigation has allowed the value and distribution of micromotions at the bone-implant interface to be estimated. It has been calculated that micromotions between 5 and $100 \mu \mathrm{m}$ occur at the bone-hip implant interface during normal gait cycles (Ramaniraka et al., 2000). The pumping action of the implant during gait cycle has also causes load fluctuation within the joint fluid. The 
pressure involved was between $2 \times 10^{-3}$ and $0.1 \mathrm{MPa}$ (Anthony et al., 1990). It is of interest to quantify the effect of micromotions at different loads on osteoblasts, and to clarify if this mechanical stimulus affects bone formation through a negative impact on osteoblast function as it has been shown for particles generated at the interfaces of orthopedic implants (Pioletti et al., 1999).

Many experimental models have been developed to mechanically stimulate cells including osteoblasts. A recent review has classified the different developed devices in function of their loading modality (Brown, 2000). None of the devices described could simulate micromotions at the bone-implant interface with amplitudes varying between 10 and $100 \mu \mathrm{m}$ and at different loads. Osteoblasts are sensitive to mechanical stimuli (Jones et al., 1991), so it would be important to study their reaction in a situation mimicking the mechanical situation at the bone-implant interface. This study presents the development of a mechanical device that applies in vitro micromotions on cells at varying defined loads, and the use of real time RT-PCR to identify the expression of several important genes for bone when using this device.

\section{Material and methods}

A mechanical device was developed allowing micromotions to be performed between two surfaces (Fig. 1A). Two constraints were needed in the development of the device to insure a proper mechanical stimulation of the cells. The first constraint was to impose a parallel alignment between the moving and resting surfaces. The resting surface consisted of a $1 \mathrm{~cm}^{2}$

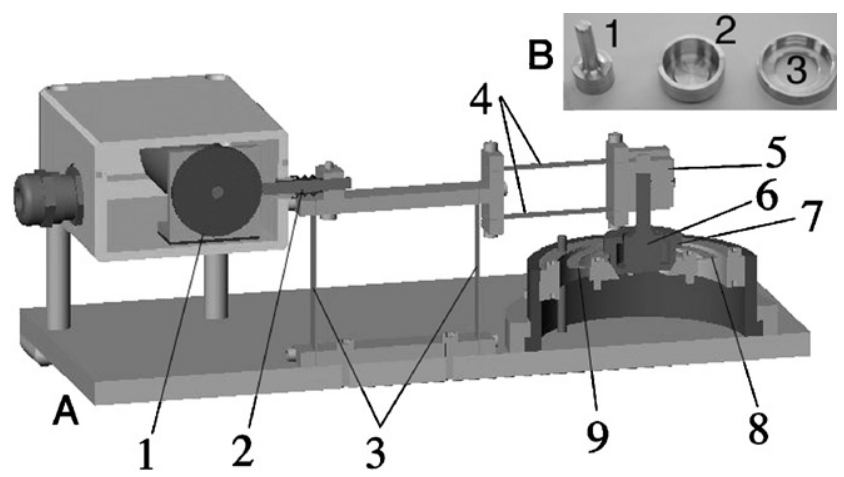

Fig. 1. Cross-sectional view of the mechanical device (A) and the well (B) on which micromotions are imposed. (A) 1. eccentric came; 2. transmission of rotation motion to linear motion; 3. pair of vertical copper elastic strips; 4. pair of horizontal copper elastic strips; 5. clamp of the moving surface; 6 . moving surface; 7 . well containing the cells (resting surface); 8. copper spider; 9. screw allowing the position of the well to be vertically adjusted. (B) 1 . moving surface; 2 . resting surface which is a well on which cells are seeded; 3 . cover of the well.

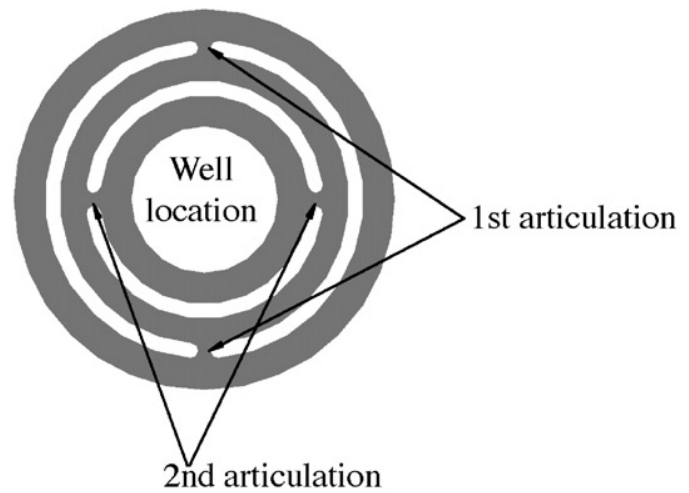

Fig. 2. Spider made of copper on which the resting surface containing the cells is placed. Due to its two articulations, an automatic alignment is obtained between the moving and resting surfaces when a load is applied.

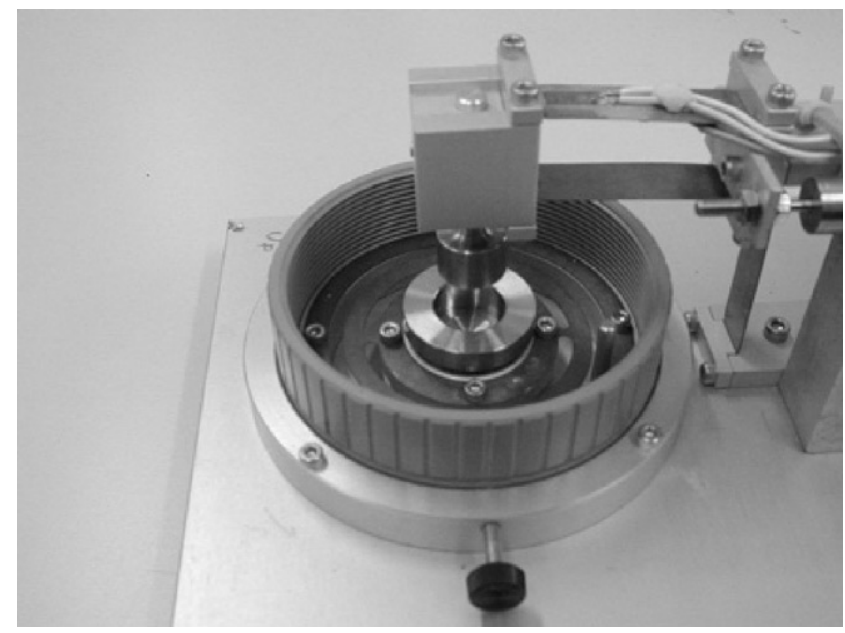

Fig. 3. View of the screw containing the spider and the well to control their vertical position. The screw allowed load between the moving and resting surfaces to be adjusted. Strain gauges can be seen on the top and bottom of one horizontal elastic strip. The strain gauges allowed to quantify the load between the moving and resting surfaces when the well containing the cells was vertically adjusted.

well containing the cells (Fig. 1B). If a misalignment was present, cells tear out invalidating the experiment. The alignment constraint was achieved by placing a copper spider below the resting surface (Fig. 2). The spider with the well containing the cells was inserted in a screw allowing the position of the well to be vertically adjusted (Fig. 3). A pair of horizontal copper elastic strips supported the moving surface. Calibrated strain gauges were placed on the top and bottom of one horizontal elastic strip, which quantified the load between the moving and resting surfaces when the well was vertically adjusted. Because of its two articulations, the spider allowed the load to be uniformly distributed between the two surfaces. The second constraint was to precisely impose motions on the micrometer scale between the 
moving and resting surfaces. Due to the precision needed for these amplitudes of motion, no play was allowed in the motion transmission. This was accomplished by a pair of vertical copper elastic strips, so that when the rotation was generated by an eccentric cam it was transformed into a precise linear motion without any play. To precisely control the micromotions, the signal of a linear transducer displacement placed on the moving surface was used in a feedback loop based on a PID. The centers of the moving and resting surfaces were aligned in the design of the device and defined the initial position before applying the displacement. It was then possible to impose, between the two surfaces, sinusoidal motions with amplitudes comprised between \pm 5 and $\pm 50 \mu \mathrm{m}$, frequencies between 0.5 and $2 \mathrm{~Hz}$, and loads between 50 and $1000 \mathrm{~Pa}$. The device, with a total length of $20 \mathrm{~cm}$, was designed to work in an incubator at $37^{\circ} \mathrm{C}$ and $100 \%$ humidity. The moving and resting surfaces were made of stainless steel grade 304 . Before use, the well and the moving parts were carefully washed with a soft brush. The pieces were then rinsed with ultrapure MQ water. The practice for surface preparation of surgical implants involves a nitric acid passivation treatment based on the ASTM F86 protocol using $30 \%$ nitric acid for $1 \mathrm{~h}$ (ASTM F86, 1999). This protocol was followed for each experiment. Finally, the pieces were rinsed several times with sterile ultrapure MQ water before being autoclaved. To evaluate for contamination an endotoxin assay, Limulus Amebocyte Lysate (BioWhittaker, Emerainville, France), was performed, which revealed no contamination with lipopolysaccharides (LPS) was present.

MG-63 osteoblast-like cells (ATCC, Rockville, MD) were seeded on the well (Fig. 1B) at a concentration of 100,000 cells $/ \mathrm{cm}^{2}$. The cells were incubated for $4 \mathrm{~h}$ before load was applied. Three assays were performed: (1) $0 \mathrm{~Pa}, 0 \mu \mathrm{m}$ (control); (2) $500 \mathrm{~Pa}, 0 \mu \mathrm{m}$; (3) $500 \mathrm{~Pa}, \pm 5 \mu \mathrm{m}$. The micromotions followed a sinusoidal function of $1 \mathrm{~Hz}$. Cell viability and gene expression analysis were performed at $24 \mathrm{~h}$. For the cell viability, cells were simultaneously double stained using fluorescein diacetate for live cell and propidium iodide for dead cells (Jones and Senft, 1985; Pioletti, et al., 1999). For the gene expression, total RNA was isolated and purified with RNeasy columns (Qiagen, Basel). The isolated RNA was reverse transcripted to cDNA with the StratScript enzyme (Stratagene, San Diego, CA). Quantitative real time RT-PCR (ABI Prism 7700, Applied Biosystem, Foster City, CA) was used to measure the gene expression of procollagen type I $\alpha 1$ chain, procollagen type I $\alpha 2$ chain, osteocalcin, osteonectin and 18S using Amplifluor Universal Detection System (Intergen, Purchase, NY). Use of the housekeeping gene (18S) allowed for normalization of the different samples and comparison of their gene expression. The control allowed for further normalization of
Table 1

Mean viability \pm SE $(n=3)$ of osteoblasts stimulated $24 \mathrm{~h}$

\begin{tabular}{lll}
\hline $\begin{array}{l}\text { Control } \\
(0 \mathrm{~Pa}, 0 \mu \mathrm{m})\end{array}$ & $500 \mathrm{~Pa}, 0 \mu \mathrm{m}$ & $500 \mathrm{~Pa}, 10 \mu \mathrm{m}$ \\
\hline $91.2 \pm 5.1$ & $89.3 \pm 4.3$ & $92.4 \pm 3.2$ \\
\hline
\end{tabular}

gene expression. Each assay was performed three times with gene expression analysis in duplicate. A two-way ANOVA tests was used followed by a Fisher leastsignificant difference test.

\section{Results}

The cell viability was not affected by the different loading condition (Table 1). The mechanical stimulations significantly $(p<0.05)$ induced a down-regulation of the tested genes except for the osteocalcin at $10 \mu \mathrm{m}$ (Fig. 4). Load alone was more potent to down-regulate the tested genes than load with micromotions. It was also interesting to note that load alone differentially modulated the gene expression of collagen type I with a significantly more important effect on the $\alpha 1$ chains as compared to $\alpha 2$ chains.

\section{Discussion}

Micromotions at the bone-implant interface have been shown to play an important role in the outcome of orthopedic implants (Goodman, 1994). There was no previously developed device, which could simulate micromotions at the bone-implant interface with amplitudes varying between 10 and $100 \mu \mathrm{m}$ and at different loads. In the present study, a mechanical device was developed, which successfully stimulated the osteoblast-like cells. The mechanical stimuli applied on the cells clearly affected their gene expression despite no effect was found on the cell viability. Combination of load and micromotions, which has been shown to occur at the bone/implant interface (e.g. Ramaniraka et al., 2000), differentially modulated the gene expression compared to load alone. These results demonstrated the usefulness of the developed device. Unlike other devices having only one mode of mechanical stimulation (Brown, 2000), the developed device allowed both micromotions and load to be applied on cells.

In the present study, the two contact surfaces were made of stainless steel, which does not match the clinical situation for a hip implant where material as stainless steel would be in contact with bone. The results obtained in this study are only an indication of possible effects produced by micromotions and load. 


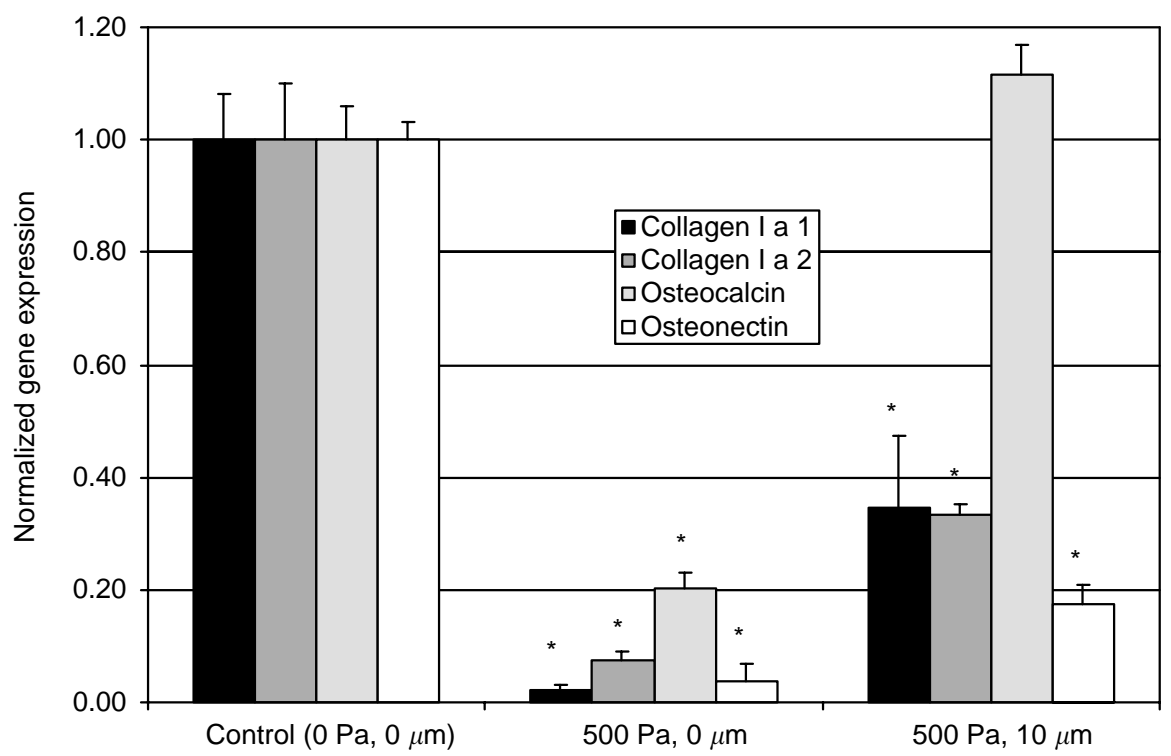

Fig. 4. Expression of the four genes tested in function of the mechanical stimulus ( ${ }^{*} p<0.05$ compared to control).

The two surfaces have a flatness of $\pm 2.5 \mu \mathrm{m}$. The MG-63 cell height is $20 \mu \mathrm{m}$ (Shin and Athanasiou, 1999). The cells are then directly stimulated with the developed device. Based on the value of compressive modulus $(2.05 \mathrm{kPa})$ for the MG-63 obtained with a cytoindentation technique (Shin and Athanasiou, 1999), these cells could experience a nominal compressive strain of $25 \%$. The modulus value obtained by Shin was based on assumption of small strain and linear elasticity. It is likely that the value of modulus increases at higher strains. Therefore, the estimation of $25 \%$ compressive strain is probably an overestimation of the strain experienced by the cells. It should be mentioned that the cell layer is not of uniform thickness with the maximum height over the cell nucleus. The corresponding nominal compressive strain is then not homogeneously distributed in the cells.

When the cells were collected after $24 \mathrm{~h}$ of stimulation, it was observed that they were either attached to the moving or resting surfaces. This fact strongly suggests that cells adhere to the two surfaces during the mechanical stimuli. Based on the cell height of $15 \mu \mathrm{m}$ corresponding to the $20 \mu \mathrm{m}$ minus the $25 \%$ compressive strain, the $10 \mu \mathrm{m}$ sliding motion induces a $75 \%$ shear strain. This value may seem very high for "usual engineer material", however, this kind of value may be supported by cells (e.g. Caille et al., 2002).

The osteoblast is mainly a secreting cell producing large quantities of type I collagen, which contains two identical $\alpha 1$ chains and a structurally similar, but genetically different, $\alpha 2$ chain (Termine and Gehron Robey, 1996). Load alone was shown to downregulate gene expression of the $\alpha 1$ chain more than the $\alpha 2$ chain. This unbalance between $\alpha 1$ and $\alpha 2$ chains gene expression might change the production of collagen protein and therefore could affect the mineralization process. Osteocalcin and osteonectin are important osteoblastic markers (Lian and Stein, 1996), which are involved in the bone mineralization process differently (Ducy and Karsenty, 1998; Termine and Gehron Robey, 1996). In the present study, differences in osteocalcin and osteonectin gene expression were found after $24 \mathrm{~h}$, suggesting that the applied mechanical stimuli may inhibit the normal mineralization process.

MG-63 cells have already been shown to be sensitive to mechanical stimuli. Stretching these cells for only 30 min stimulated not only the expression of c-fos, but also the expression of BMP-2 and BMP-4 and their receptor gene, ALK-3 (Sakoda et al., 1999). It should be noted that the sensitivity to mechanical forces may be different during the different stages of the osteoblast life (Kaspar et al., 2000). MG-63 cells are considered as relatively immature osteoblasts with respect to their low production of alkaline phosphatase. It would then be interesting to repeat the experiments with more mature osteoblasts.

The new device was developed to mimic the situation at the bone-implant interface and to quantify the corresponding cells reaction. Micromotions and load were shown to affect the behavior of osteoblasts by down-regulating the expression of genes necessary for the creation of organic extracellular matrix (collagen type I) as well as for genes involved in the mineralization process (osteocalcin, osteonectin). Lending evidence that the formation of fibrous tissue around orthopedic implants could be due to an osteoblast gene modulation induced by mechanical stimulation. 


\section{Acknowledgements}

This work was supported by Grant \#309 from the Leenaards Foundation, and the manuscript was critically reviewed by Davey Smith, MD.

\section{References}

Anthony, P.P., Gie, G.A., Howie, C.R., Ling, R.S., 1990. Localised endosteal bone lysis in relation to the femoral components of cemented total hip arthroplasties. Journal of Bone and Joint Surgery, Britain 72, 971-979.

Aspenberg, P., Herbertsson, P., 1996. Periprosthetic bone resorption. Particles versus movement. Journal of Bone and Joint Surgery, Britain 78, 641-646.

ASTM F86, 1999. Medical devices; emergency medical services. American Society for Testing and Materials, Pennsylvania, USA.

Brown, T.D., 2000. Techniques for mechanical stimulation of cells in vitro: a review. Journal of Biomechanics 33, 3-14.

Caille, N., Thoumine, O., Tardy, Y., Meister, J.J., 2002. Contribution of the nucleus to the mechanical properties of endothelial cells. Journal of Biomechanics 35, 177-187.

Clarke, I.C., Campbell, P., Kossovsky, N., 1992. Debris-mediated osteolysis - a cascade phenomenon involving motion, wear, particulates, macrophage induction, and bone lysis. In: St. John, K.R. (Ed.), Particulate Debris from Medical Implants: Mechanisms of Formation and Biological Consequences, ASTM STP 1144. American Society for Testing and Materials, Philadelphia, pp. 7-26.

Ducy, P., Karsenty, G., 1998. Genetic control of cell differentiation in the skeleton. Current Opinion on Cell Biology 10, 614-619.

Goodman, S.B., 1994. The effects of micromotion and particulate materials on tissue differentiation. Bone chamber studies in rabbits. Acta Orthopaedica Scandinavica, Supplementum 258, 1-43.

Hori, R.Y., Lewis, J.L., 1982. Mechanical properties of the fibrous tissue found at the bone-cement interface following total joint replacement. Journal of Biomedical Materials Research 16, 911-927.

Jasty, M., Bragdon, C., Burke, D., O'Connor, D., Lowenstein, J., Harris, W.H., 1997. In vivo skeletal responses to porous-surfaced implants subjected to small induced motions. Journal of Bone and Joint Surgery, America 79, 707-714.

Jones, K.H., Senft, J.A., 1985. An improved method to determine cell viability by simultaneous staining with fluorescein diacetatepropidium iodide. Journal of Histochemistry and Cytochemistry 33, 77-79.

Jones, D.B., Nolte, H., Scholubbers, J.G., Turner, E., Veltel, D., 1991. Biochemical signal transduction of mechanical strain in osteoblastlike cells. Biomaterials 12, 101-110.

Kaspar, D., Seidl, W., Neidlinger-Wilke, C., Ignatius, A., Claes, L., 2000. Dynamic cell stretching increases human osteoblast proliferation and CICP synthesis but decreases osteocalcin synthesis and alkaline phosphatase activity. Journal of Biomechanics 33, 45-51.

Lian, J.B., Stein, G.S., 1996. Osteoblast Biology. Academic Press, San Diego.

Pioletti, D.P., Takei, H., Kwon, S.Y., Wood, D., Sung, K.-L.P., 1999. The cytotoxic effect of titanium particles phagocytosed by osteoblasts. Journal of Biomedical Materials Research 46, 399-407.

Ramaniraka, N.A., Rakotomanana, L.R., Leyvraz, P.F., 2000. The fixation of the cemented femoral component. Effects of stem stiffness, cement thickness and roughness of the cement-bone surface. Journal of Bone and Joint Surgery, Britain 82, 297-303.

Sakoda, S., Shin, H.Y., Yamaji, K., Takasaki, I., Furuzono, T., Kishida, A., Akashi, M., Kubo, T., Nagaoka, E., Maruyama, I., Kitajima, I., 1999. Mechanical stretching of human osteoblast-like cells stimulates bone morphogenic proteins and macrophage colony-stimulating factor productions. Pathophysiology 6, 63-69.

Shin, D., Athanasiou, K., 1999. Cytoindentation for obtaining cell biomechanical properties. Journal of Orthopaedic Research 17, 880-890.

Termine, J.D., Gehron Robey, P., 1996. Bone matrix proteins and the mineralization process. In: Favus, M.J. (Ed.), Primer on the Metabolic Bone Diseases and Disorders of Mineral Metabolism, 3rd Edition. Lippincott-Raven, Philadelphia, pp. 24-28. 